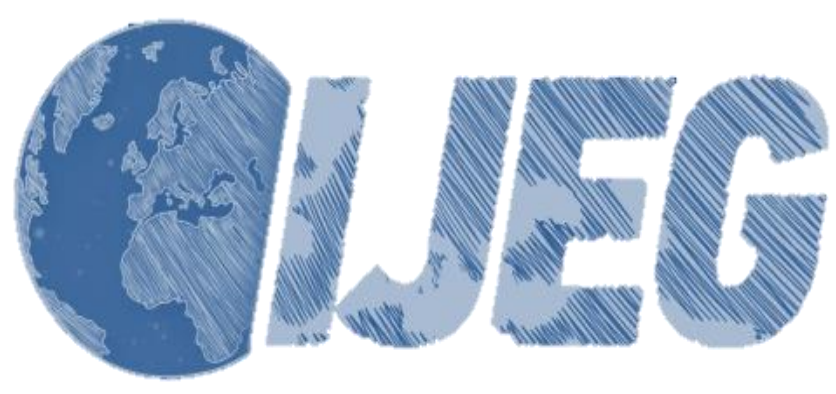

International Journal of Engineering and Geosciences (IJEG), Vol; 4, Issue; 2, pp. 088-093, June, 2019, ISSN 2548-0960, Turkey, DOI: Your 10.26833/ijeg.473944

\title{
THE DEFORMATION ANALYSIS USING HYPOTHESIS TESTS.
}

\author{
Ulku Kirici Yildirim $^{1 *}$ and Yasemin Sisman ${ }^{1}$ \\ ${ }^{1}$ Ondokuz Mayis University, Engineering Faculty, Department of Geomatic Engineering, Samsun, Turkey (ulku.kirici/ \\ ysisman@ omu.edu.tr); ORCID 0000-0002-3569-4482; ORCID 0000-0002-6600-0623
}

*Corresponding Author, Received: 24/10/2018, Accepted: 25/02/2019

\begin{abstract}
There are temporary or permanent physical changes depending on time in earth surface. These physical changes named as deformation. The magnitude and direction of the deformation effect must be measured and controlled. The geodetic deformation network is established to determine the deformation movements and the deformation measurements are made. Then, the point coordinates are calculated used the free network adjustment. So, the different point coordinates were obtained according to measured time. The difference of point coordinate must be test to decide as significant or insignificant. Thus, the significance test based hypothesis test can be made. In this study, deformation network was established in Toybelen village of Samsun province and the deformation measurements were made periodically. The deformation network was create with using 15 points and one of these point is the control point. This deformation network measured in two periods used the global positioning system. Evaluation was made using the Topcon program and point coordinates were obtained. Differences in point coordinates received and these differences were significant tested. The program written in the matlab program was used for this test. Finally, coordinate values compared in two periods and movement points have been identified.
\end{abstract}

Keywords: Deformation, Hypothesis Tests, Significant Tests, Outlier Measurement Tests 


\section{INTRODUCTION}

Deformation is defined as shape changes that occur in or around major engineering structures due to tectonic plate movements, landslides, displacement of the earth core, or artificial events caused by human hands. Measurement made at different periods for monitoring these changes are called deformation measurements. The determination and interpretation of these changes is called deformation analysis (Tanır, 2000). The aim of deformation analysis is the detection; localization and modelling of point movements in multiply measured networks. Such an analysis provides valuable information about the deformations of physical and man-made objects on the earth surface. In the deformation studies, geodetic observations are repeated at different epochs of time. The observations of each epoch are adjusted independently. From coordinate differences between the epochs, the parameters of the deformation model are estimated and conclusions on the object deformations are drawn (Kaplan at al., 2004). These conclusions examine and compared.

The aim of the study is to determine the points of deformation in the study area designated as Toybelen village. Toybelen village is located in Samsun province. Firstly, the polygon network was laid in the region for this purpose. Then three periods were measured in the region and point coordinates are calculated. The significance test was applied to the calculated coordinates and the results were commented. These application were done in matlab programming language.

\section{DEFORMATION ANALYSIS}

Any object, natural or man-made, undergoes changes in space and time. Deformation refers to the changes a deformable body undergoes in it is shape, dimension, and position. Since the results of deformation surveys are directly relevant to the safety of human life and engineering surveying, recently deformation analysis has become more important (Kaplan et al., 2004). The changes that occur in the shape of an object, its position and its size due to any effect are called deformation. The upper layers of the earth's crust are in constant motion both horizontally and vertically due to factors such as change of ground water level, tectonic phenomena, landslides, etc. Therefore, any large man-made structures such as bridges, high rise buildings, dams, etc., which are built on the surface of the earth are subject to deformation This deformation needs to be monitored continuously for safety assessment purpose (Setan et al., 2001)

The traditional task of deformation analysis is the investigation of movements and displacements of an object with respect to space and time. Driven by the development of measuring and analysis techniques and the need of interdisciplinary approaches for solutions, the goal of geodetic deformation analysis is nowadays to proceed from a merely phenomenological description of the deformations of an object to the analysis of the process which caused the deformations (Heunecke et al., 2000).

There are two main purpose of deformation analysis. These are:

- Geometric condition of the deformed object (location and shape change)
- To learn about physical condition (deformation relation with effective force) (Bayrak, 2003)

Deformation are analyzed in different model according to type of the problem and method of the measurement.

These models are:

- $\quad$ Non-time-dependent static models

- Kinematic models that depend on time and position

- Dynamic models that depend on the time and location of the cause of motion.

There are static, kinematic and dynamic models in deformation analysis. The static deformation model consists in a purely geometrical comparison of the state of an object represented by its characteristic points at different time periods. Such kind of deformation analysis is applied by the geodetic network method in geodesy.

The stages in determining deformations by using the geodetic network method are as follows:

- Setting up monitoring networks: A monitoring network, which consists of deformation control points which are established on the object under investigation and control points which are established out of the stable area, is set up according to optimum aim functions.

- Taking observations: The periodic measurements are conducted within a determined periodic interval on monitoring network.

- Evaluating observations: In advance of deformation analysis, free network adjustment which shows realistic form internal precision of network is performed.

- Deformation analysis: Deformation analysis is made using coordinates of different periods with a suitable static deformation method and the results are interpreted (Tanır Kayıkçı et al., 2012)

Also, the deformation monitoring can be determinate with significance test of coordinate difference. The significance test is an application of hypothesis test.

\subsection{Hypothesis Test}

The proposed solution of scientific methods is expressed in practice in the form of hypothesis and research questions. So the hypothesis is simply an assertion a theory. As a solution, this claim is tried to be confirmed. The process of establishing a hypothesis and confirming or falsifying this hypothesis and reaching a decision at the end is called the hypothesis test. Establishing a hypothesis; expresses the determination of two propositions which are complementary to each other. So hypotheses in hypothesis tests are expressed by two propositions. The first of them is expressed by 'null hypotheses', ' $\mathrm{H}_{\mathrm{o}}$ '. The second proposition is the expression ' $\mathrm{H}_{1}$ ', which is called 'alternative hypothesis'(Demir, 2017).

A statistical test method can be briefly summarized as follows:

-Establishment of zero hypothesis $\mathrm{H}_{0}$ and alternative hypothesis $\mathrm{H}_{1}$

Bi-directional hypothesis testing

$$
\begin{aligned}
& H_{0}: \mu=\mu_{0} \\
& H_{1}: \mu \neq \mu_{0}
\end{aligned}
$$


Unidirectional of Hypothesis Tests

$$
\begin{array}{ll}
H_{0}: \mu=\mu_{0} & H_{0}: \mu=\mu_{0} \\
H_{1}: \mu>\mu_{0} \text { or } \quad H_{1}: \mu<\mu_{0}
\end{array}
$$

-Generation of known distribution test value with using data

- Choice of probability of error $\alpha$ and production of limit values of test size using distribution rulers

-Determining whether the size of the test is in the Acceptance Zone or the Red Zone

\subsubsection{Model Hypothesis Testing}

Model hypothesis testing should be performed before proceeding to deformation analysis. The modeling hypothesis test is used to check whether the relations between the measurements and the unknowns are appropriate in the adjustment, the sensitivities of the measures and the correlations between them.

As a result of evaluation of similar conditions and same kind of measurements, root mean square error finding before adjustment is a priori $\left(\mathrm{s}_{0}\right)$ value, root mean square error finding after adjustment is a posteriori $\left(\mathrm{m}_{0}\right)$ value (Ünver et al., 2015).

Null hypothesis for model hypothesis testing;

$$
H_{0}: E\left\{m_{0}^{2}\right\}=E\left\{s_{0}^{2}\right\}=\sigma_{0}^{2}
$$

Alternative hypothesis in one-way tests,

$$
\begin{array}{ll} 
& H_{S_{1}}: E\left\{m_{0}^{2}\right\}<E\left\{s_{0}^{2}\right\} \\
\text { or } \quad & H_{S_{1}}: E\left\{m_{0}^{2}\right\}>E\left\{s_{0}^{2}\right\}
\end{array}
$$

is established. Two-way tests,

$$
H_{S_{2}}: E\left\{m_{0}^{2}\right\} \neq E\left\{s_{0}^{2}\right\}
$$

is established as the formula.

Determined Test Value “Eq. (1)”;

$$
T=\frac{m_{0}^{2}}{s_{0}^{2}} ; \quad m_{0}>s_{0}
$$

Then it is compared then Table value "Eq. (2)".

$$
q_{1}=F_{f_{1}, f_{2}, 1-\alpha} \text { or } q_{2}=F_{f_{1}, f_{2}, 1-\frac{\alpha}{2}}
$$

If the test value is smaller than the table value $(\mathrm{T}<\mathrm{q})$, the adjustment model is valid; if it is greater $(T>q)$ the adjustment model is not valid (Bayrak, 2003).

\subsubsection{Outlier measurement test}

No matter how careful deformation measurements are made, errors that occur during measurements cannot be prevented. However, if these errors are not detected during the evaluation of the measurements, they cause to a wrong conviction about the presence and direction of the deformation. These errors, which lead to the invalidity of the mathematical model of the adjustment, can be eliminated by an outlier measurement tests. The aim of the outlier measurement tests is to determine a measure, which is the largest correction. After the outlier with the largest amount of error is determined and eliminated, the remaining other measures are re-tested again, and this process is continued until the outlier measurements end (Bayrak, 2003; Tanır, 2000).

The differences between the adjustment coordinates obtained after removal of the outlier measurements in each period may not yet reflect the full-scale deformation due to random errors in the measurements. In this case, to analyze the significance of the changes in the coordinates, deformation analysis is carried out in which the coordinate differences are tested by statistical methods (Altıntaş, 2014).

\subsubsection{Static significance test}

Static model is the most basic method whether motion occurs in the object and determining the point coordinate differences determined at various periods of the deformation network including the object and it surroundings with statistical significance test (Bayrak., 2003). To determine movements with a static model, a deformation network is measured at different observation times with geodetic methods. A functional model, solved according to the least squares method, is constituted for each observation period. Thus, coordinate vectors ( $\mathrm{x}_{1}$ and $\left.\mathrm{x}_{2}\right)$, their variance- covariance matrices ( $Q_{x_{1} x_{1}}$ and $Q_{x_{2} x_{2}}$ ) and the sum of squares of residuals to be added to observations $\left(v_{1}^{T} p_{1} v_{1}\right.$ and $\left.v_{2}^{T} p_{2} v_{2}\right)$ for the $\mathrm{t}_{1}$ and $\mathrm{t}_{2}$ periods are computed separately.

Then, the coordinate difference vector (d) is computed as follows "Eq. (3)".

$$
d=x_{1}-x_{2}
$$

The covariance matrix ( $Q_{d d}$ ) of vector d is calculated as follows "Eq. (4)":

$$
Q_{d d}=Q_{x_{1} x_{1}}+Q_{x_{2} x_{2}}
$$

Root mean square error "Eq. (5)";

$$
m_{0}=\sqrt{\frac{V_{1}^{T} V_{1}+V_{2}^{T} V_{2}}{(n-u+d)+(n-u+d)}}
$$

Test value for a hypothesis test "Eq. (6)";

$$
T=\frac{d}{m_{0} \sqrt{Q_{d d}}}
$$


Table value;

$$
\begin{aligned}
& f=f_{1}+f_{2} \\
& f_{i}=n_{i}-u_{i}+d \\
& h=\operatorname{rang}\left(Q_{x_{1} x_{1}}\right)=\operatorname{rang}\left(Q_{x_{2} x_{2}}\right) \\
& q=F_{h, f, 1-\alpha}
\end{aligned}
$$

are determined.

If the test value $(\mathrm{T})$ is greater than the F-distribution table value, the null hypothesis is rejected and point positions probably change (Yalçınkaya et al., 2004). But if F-distribution table value is greater than test value (T) null hypothesis is true and there is no movement in point positions.

\section{APPLICATION AND RESULTS}

In this study landslide area in Toybelen village of Atakum district of Samsun province was chosen as study area. Firstly, a polygon network consisting of 15 points has been laid. One of these point is selected as control point. These points Show that the Figure 1 and Figure 2.

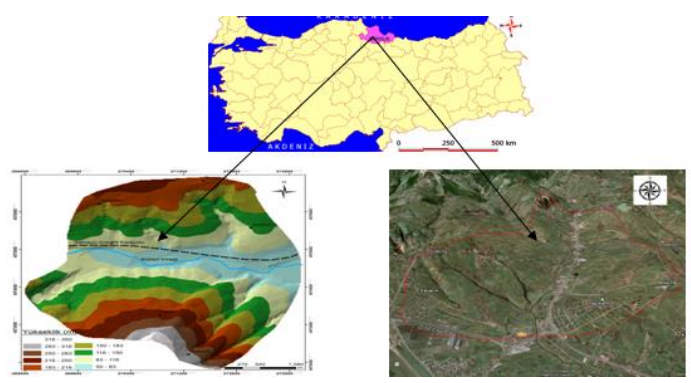

Figure.1 Application area

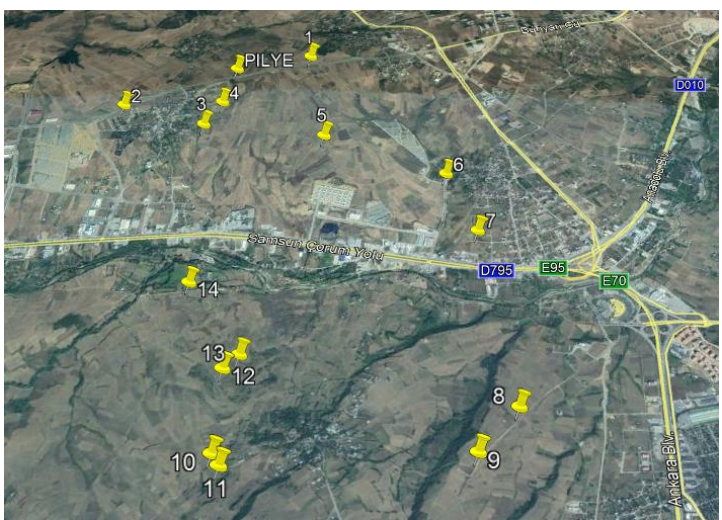

Figure 2: Study area

Three periods of measurements were made on the study area approximately four months apart. These measurements were made in static measurement method. After measurements were completed, post processing was done in the Topcon Tools. The data were evaluated in Matlab programming language and the results were compared. The version of the matlab program used is MatlabR2017a. The Matlab program used is licensed by Ondokuz Mayis University. Then coordinates and the varyans-covaryans matrix of the points were calculated with the measurements. $d$ differences were calculated and significant test was made for these differences. Finally, Test value (T) and Table value (q) were obtained.

The results obtained are as in the following table. The first three columns in table show that determined test value (T) comparison first and second period measurement in application. Other measurement shows

\begin{tabular}{|c|c|c|c|c|c|c|}
\hline \multicolumn{4}{|c|}{$\begin{array}{c}\text { First and Second Period } \\
\text { Measurements }\end{array}$} & \multicolumn{3}{|c|}{$\begin{array}{c}\text { First and Third Period } \\
\text { Measurement }\end{array}$} \\
\hline & $\mathrm{TV}(\mathrm{x})$ & TV(y) & $\mathrm{TV}(\mathrm{z})$ & $\mathrm{TV}(\mathrm{x})$ & TV $(y)$ & $\mathrm{TV}(\mathrm{z})$ \\
\hline 1 & 1.628 & 1.928 & 4.582 & 7.417 & 2.830 & 0.247 \\
\hline 2 & 1.628 & 1.427 & 14.949 & 0.961 & 2.417 & 13.076 \\
\hline 3 & 6.085 & 2.983 & 0.857 & 46.976 & 12.829 & 0.302 \\
\hline 4 & 19.142 & 0.789 & 1.239 & 106.863 & 2.005 & 7.664 \\
\hline 5 & 4.722 & 1.496 & 3.583 & 13.418 & 6.313 & 4.267 \\
\hline 6 & 2.379 & 5.058 & 0.576 & 3.709 & 10.659 & 6.566 \\
\hline 7 & 2.504 & 2.053 & 1.077 & 2.335 & 6.950 & 5.329 \\
\hline 8 & 2.629 & 0.576 & 11.693 & 3.022 & 4.066 & 4.423 \\
\hline 9 & 1.502 & 2.053 & 14.473 & 3.434 & 1.181 & 11.373 \\
\hline 10 & 8.388 & 5.584 & 9.440 & 82.963 & 20.109 & 30.932 \\
\hline 11 & 1.753 & 2.329 & 0.926 & 28.570 & 5.549 & 3.681 \\
\hline 12 & 6.015 & 1.063 & 14.796 & 5.389 & 1.606 & 9.546 \\
\hline 13 & 0.601 & 2.546 & 9.864 & 18.917 & 1.606 & 3.651 \\
\hline 14 & 0.902 & 1.363 & 3.970 & 15.617 & 9.524 & 4.971 \\
\hline P001 & 15.109 & 6.431 & 6.043 & 15.726 & 1.105 & 22.866 \\
\hline
\end{tabular}
that comparison first and third period measurement in application.

Table 1 Calculated Test Value (TV)

After the test values are calculated, the table value is passed. The table value (q) found as 6.35 in the study. Then the table values and test values were compared. The points whose test value $(\mathrm{T})$ is greater than table value $(\mathrm{F})$ are marked. Then in both periods, the points that are greater than the test value are marked. These value are shown that Table 2 . 
Table 2: Points that move in both periods

\begin{tabular}{|c|c|c|c|c|c|c|}
\hline \multicolumn{4}{|c|}{$\begin{array}{c}\text { First and Second Period } \\
\text { Measurements }\end{array}$} & \multicolumn{3}{|c|}{$\begin{array}{c}\text { First and Third Period } \\
\text { Measurement }\end{array}$} \\
\hline & $\mathrm{TV}(\mathrm{x})$ & $\mathrm{TV}(\mathrm{y})$ & $\mathrm{TV}(\mathrm{z})$ & $\mathrm{TV}(\mathrm{x})$ & $\mathrm{TV}(\mathrm{y})$ & $\mathrm{TV}(\mathrm{z})$ \\
\hline 1 & 1.628 & 1.928 & 4.582 & 7.417 & 2.830 & 0.247 \\
\hline 2 & 1.628 & 1.427 & (14.949) & 0.961 & 2.417 & 13.076 \\
\hline 3 & 6.085 & 2.983 & 0.857 & 46.976 & 12.829 & 0.302 \\
\hline 4 & (19.142 & 0.789 & 1.239 & 106.863 & 2.005 & 7.664 \\
\hline 5 & 4.722 & 1.496 & 3.583 & 13.418 & 6.313 & 4.267 \\
\hline 6 & 2.379 & 5.058 & 0.576 & 3.709 & 10.659 & 6.566 \\
\hline 7 & 2.504 & 2.053 & 1.077 & 2.335 & 6.950 & 5.329 \\
\hline 8 & 2.629 & 0.576 & 11.693 & 3.022 & 4.066 & 4.423 \\
\hline 9 & 1.502 & 2.053 & 14.473 & 3.434 & 1.181 & 11.373 \\
\hline 10 & 8.388 & 5.584 & 9.440 & 82.963 & 20.109 & 30.932 \\
\hline 11 & 1.753 & 2.329 & 0.926 & 28.570 & 5.549 & 3.681 \\
\hline 12 & 6.015 & 1.063 & 14.790 & 5.389 & 1.606 & 9.546 \\
\hline 13 & 0.601 & 2.546 & 9.864 & 18.917 & 1.606 & 3.651 \\
\hline 14 & 0.902 & 1.363 & 3.970 & 15.617 & 9.524 & 4.971 \\
\hline P001 & 15.109 & 6.431 & 6.043 & 15.726 & 1.105 & 22.866 \\
\hline
\end{tabular}

Thus in three periods of measurements;

- $\quad \mathrm{z}$ axis of point 2

- $\quad x$ axis of point 4

- $\quad \mathrm{z}$ axis of point 9

- $\quad x$ and $z$ axis of point 10

- $\quad \mathrm{z}$ axis of point 12

- $\quad \mathrm{x}$ axis of point $\mathrm{P} 001$

motion detected.

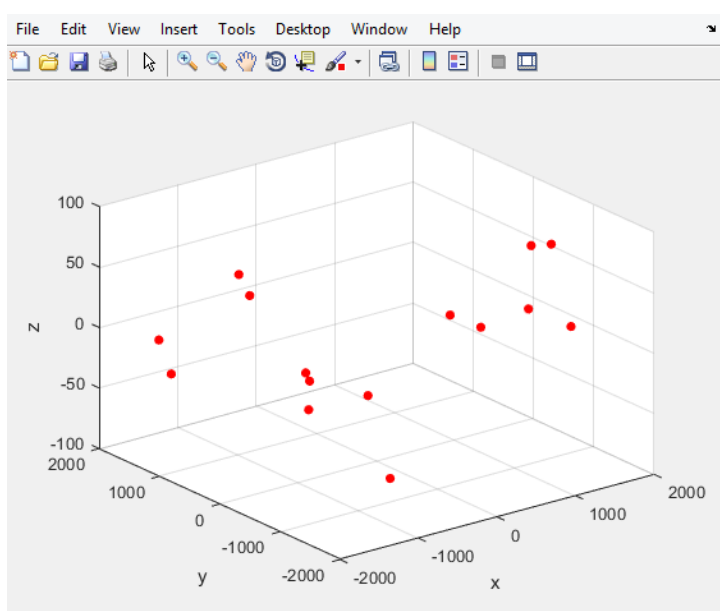

Figure 3. Plotted point distributions in Matlab

\section{DISCUSSION AND EVALUATION}

When looking at the values, there was no motion detection in y axis. Generally, it seen that movement in the $\mathrm{z}$ axis. Also the application period progresses were observed that the test values of the detected points were increased. When the movement observed point is looked, it is observed that the values in point $\mathrm{x}$ and $\mathrm{y}$ axis in point 2 are very small but move in $\mathrm{z}$ axis. Point 4 has only movement in the $\mathrm{x}$ axis but test value was seen to increase too much in these axis. Points 1, 5, 6, 7 and 8 are close to each other when looking at the study area. No motion was observed at these points. Point 9 has only movement in the $\mathrm{z}$ axis. Point 10 has been observed motion in both $\mathrm{x}$ and $\mathrm{z}$ axis. At point 10 , the test values were seen to increased too much in $\mathrm{x}$ and $\mathrm{z}$ axis. Point 12 has only movement in the $\mathrm{z}$ axis and lastly point $\mathrm{P} 001$ has only movement in the $\mathrm{x}$ axis. It is seen that the test values of point $\mathrm{P}$ is very close to each other in two evaluations.

In this study, three period measurement were done and finding these results. The results obtained are initial results. It is necessary to increase the number of measurements and continue to work. As the number of measurement periods increases, the continuity of the observed points will occur. Thus, if there is a danger in the region, it will be revealed and necessary precautions can be taken.

\section{REFERENCES}

Altıntaș F. (2014). Gümüşhane -Trabzon Hattı Boyunca Yerkabuğu Hareketlerinin GNSS Verileri İle İzlenmesi, Yüksek Lisans Tezi, Fen Bilimleri Enstitüsü, Gümüşhane Üniversitesi, Gümüşhane.

Bayrak T. (2003). Heyelanlar için Bir Dinamik Deformasyon ve Bir Dinamik Hareket Yüzeyi Modelinin Oluşturulması, Doktora Tezi, Fen Bilimleri Enstitüsü, Karadeniz Teknik Üniversitesi, Trabzon.

Demir E. (2017). İstatistik Ders Notları [PDF belgesi]. Online Web site: 12 Temmuz 2018 tarihinde http://www.academia.edu/30931820/Istatistik_Ders_Not larim_E.Demir_2017_.pdf adresinden erişildi.

Heunecke O., Welsch W. (2000). Terminology and Classification of Deformation Models in Engineering Surveys, Journal of Geospatial Engineering, Vol. 2, No.1, pp.35-44, Hong Kong.

Kaplan M.O., Ayan T., Erol S. (2004). The Effects of Geodetic Configuration of the Network in Deformation Analysis, FIG Working Week 2004 Athens, Greece, May 22-27, 2004.

Setan H.,Singh R. (2001). Deformation Analysis Of A Geodetic Monitoring Network, Geomatica. Vol. 55, No. 3.

Tanır E. (2000). Deformasyon Analizinde Statik Değerlendirme Yöntemleri, Yüksek Lisans Tezi, Fen Bilimleri Enstitüsü, Karadeniz Teknik Üniversitesi, Trabzon.

Tanır Kayıkçı E., Yalçınkaya M. (2012). Determination of Horizontal Movements by Static Deformation Models: A Case Study on the Mining Area, Experimental Techniques 39 (2015) 70-81.

Ünver Ö.,Gamgam H.,Altunkaynak B. (2015). Temel İstatistik Yöntemler, Seçkin Yayınevi. 
International Journal of Engineering and Geosciences (IJEG),

Vol; 4, Issue; 2, pp. 088-093, June, 2019,

Yalçınkaya M., Bayrak T. (2004). Comparison of Static and Dynamic Geodetic Deformation Models for
Kutlugün Landsline in Northeastern Turkey, Natural Hazards (2005) 34: 91-110. 